\title{
Single-port laparoscopy for treatment of concomitant adnexal masses and chole-cystectomy or appendectomy.
}

\author{
Yusuf Aytaç Tohma ${ }^{1}$, Tugan Tezcaner ${ }^{2}$, Emre Günakan ${ }^{3}$, İrem Küçükyıldız ${ }^{4}$, Mustafa Kemal Takal' \\ Hulusi Bülent Zeyneloğlu' ${ }^{1}$, Polat Dursun ${ }^{*}$ \\ ${ }^{1}$ Department of Obstetrics and Gynecology, Baskent University School of Medicine, Ankara, Turkey \\ ${ }^{2}$ Department of General Surgery, Baskent University School of Medicine, Ankara, Turkey \\ ${ }^{3}$ Department of Obstetrics and Gynecology, Keçiören Teaching and Research Hospital, Ankara, Turkey \\ ${ }^{4}$ Department of Obstetrics and Gynecology, Etlik Zübeyde Hanım Women's Health Teaching and Research Hospital, \\ Ankara, Turkey \\ ${ }^{5}$ Department of Obstetrics and Gynecology, Medical Park Uşak Hospital, Uşak, Turkey
}

\begin{abstract}
Objective: To report our experience treating adnexal masses concomitant appendectomy or cholecystectomy using of the Single-Incision Laparoscopic Surgery (SILS).

Methods: Nine women with symptomatic and persistent adnexal masses with appendicitis or cholecystitis are included to study. Removal of adnexal masses and performed appendectomy or cholecystectomy via single-incision laparoscopic surgery using a combination of the SILSTM port and straight non-roticulating laparoscopic instruments.

Results: 6 patients had symptomatic complex adnexial masses and 3 patients had symptomatic myoma uteri. In 2 of the patients had myoma uteri appendectomy (hysterectomy+bso+appendectomy) were performed concomitantly and in 1 of patients had myoma uteri cholecystectomy (hysterectomy+BSO +cholecystectomy) were performed concomitatly. In 4 of the patients had symptomatic adnexal masses appendectomy (hysterectomy+bso or uso or cystectomy+appendectomy) were performed concomitantly and in 2 of patients had complex adnexial masses cholecystectomy (hysterectomy+USO or USO+cholecystectomy) were performed concomitatly. Mean duration of surgery was $128 \mathrm{~min}$. None of the patients converted to laparotomy. All patients were discharged on postoperative d 1 . None of the patients required readmission to hospital. Post-surgery all patients reported that they were satisfied with their incision and cosmetic results.

Conclusion: SILS can result in better aesthetic result than conventional laparoscopy for the treatment of adnexal masses concomitant appendectomy or cholecystectomy.
\end{abstract}

Keywords: Single port, Single incision laparoscopic surgery, Cholecystectomy, Adnexal mass, Appendectomy. Accepted on January 22, 2018

\section{Introduction}

Laparoscopy is recommended as a standard treatment of adnexal masses and benign general surgical indications such as gallbladder diseases and appendecitis [1,2]. Conventional laparoscopy has several advantages such as less postoperative pain, shorter hospital stays and better cosmesis are compared with the laparotomy. Generally, skin incision for $\geq 3$ trocars which is risked for tracor site bleeding, herniation, infection and adhesion formation are used in classical laparoscopic surgery for gynecological and general surgical indications [1]. But laparoscopic surgical techniques are rapidly evolving and aim of this effort is decreasing parietal trauma and visible scars [1]. As a result, the use of single-port laparoscopy has increased over the last 20 years. Single-Incision Laparoscopic Surgery (SILS) can result in less tracor site bleeding, herniation, infection and adhesion formation and especially better cosmesis than is the case with classical laparoscopy, which is usually, performed with multiple trocar incisions [2]. Currently, single-port laparoscopy is used as a standard technique for laparoscopic appendectomy and cholecystectomy. It is also used for nephrectomy, hysterectomy, cystectomy, splenectomy, gastric bypass, hernia repair and colon resection, but the use of SILS for these procedure are not yet common $[3,4]$.

Gynecologic surgery for adnexal masses and appendectomy or cholecystectomy can be performed together with using 
conventional laparoscopy [5]. It has been several advantages for patients such as reduced morbidity, decreased psychological stress and anaesthesia exposure and a single hospitalization compared to the two procedures per-formed separately [6,7]. However conventional laparoscopic surgery requires five or six trocars for concomitant surgery of this indications and risk of trocar-site bleeding, infection, adhesion formation, and herniation is increasing with increasing trocar number $[6,7]$.

In this study, we report on nine patients who had symptomatic and persistent adnexal masses concomitant with appendicitis or cholecystitis and treated with SILS. To our knowledge, this is the first case series about using of SILS for concomitantly general surgical and gynecologic indications.

\section{Materials and Methods}

Medical records of all patients who had symptomatic and persistent adnexal masses concomitant with appendicitis or cholecystitis and treated with SILS at our tertiary centre were included in our retrospective case series. Patients who had adnexal masses with suspected malignant as a result of imaging and laboratory studies were excluded from the study.

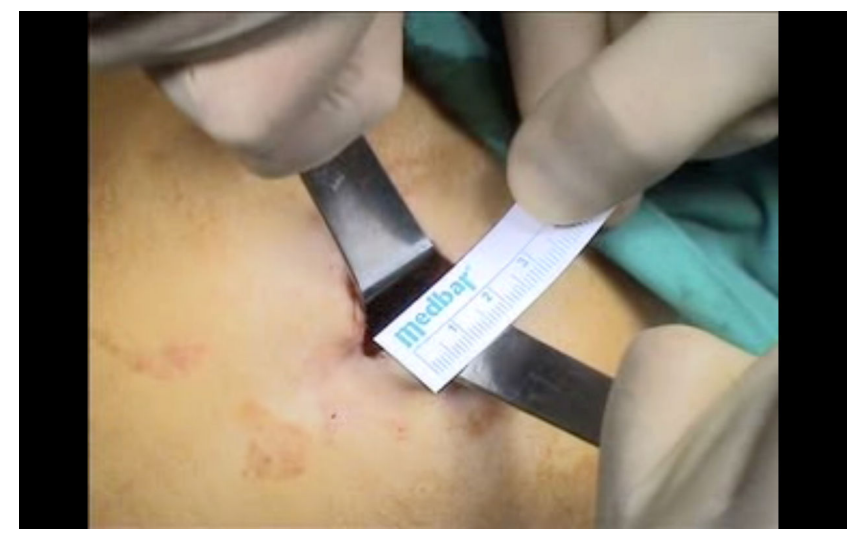

Figure 1. Incision for SILS port.

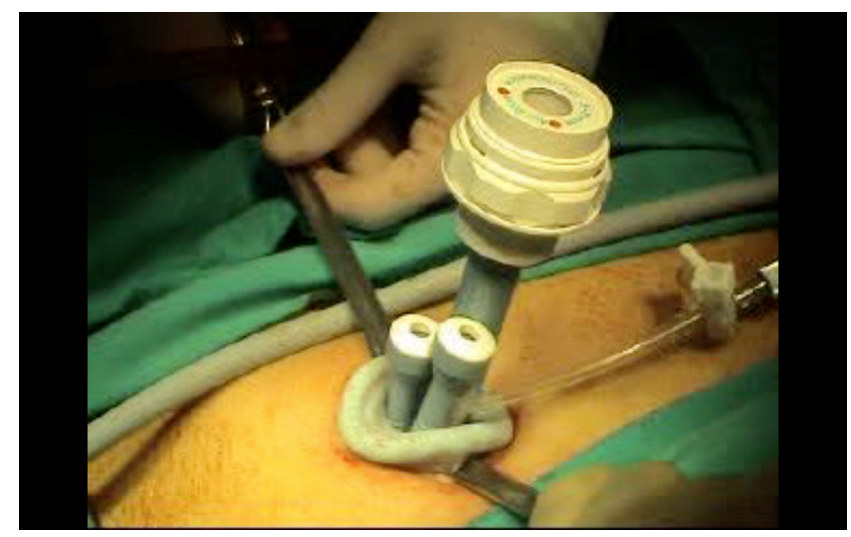

Figure 2. SILS port and instruments positions.

SILS was performed as previously reported at study of Polat et al. [8]. Briefly, a $2 \mathrm{~cm}$ longitudinal umbilical skin incision was made and then the fascia was exposed with dissection and the help of retractor. After exposure of fascia, it cut with a no. 11 scalpel blade, and the peritoneum was incised using Metzenbaum scissors (Figure 1). No other extraumbilical skin incisions were done. We used a SILSTM port (Covidien, Norwalk, CT) with three access inlets for the procedure and it was inserted transumbilically with the help of Heaney clamps. After insertion of port, $\mathrm{CO}_{2}$ was insufflated to be $12 \mathrm{mmHg}$ intraabdominal pressure for pneumaperitoneum (Figure 2). We used a $10 \mathrm{~mm}$ rigid video laparoscope and two classical nonroticulating straight laparoscopic instruments for all procedure. In addition to these instruments, we used bipolar and monopolar cautery, dissection forceps, and suction-irrigation devices when needed. If collision of the instruments resulted in inadequate surgical movement to allow for dissection, cutting, or coagulation, the surgeon would change the placement of the instruments, his position (from the patient's lateral side to the patient's head), or the placement of the endoscope in order to perform the necessary movements. The specimen was retracted with an endobag via umbilical incision. Fascial layers of the umbilicus were simultaneously closed with using No. 1 vicryl interrupted sutures. All surgical procedures had been performed by one gynecologic surgeon and one general surgeon.

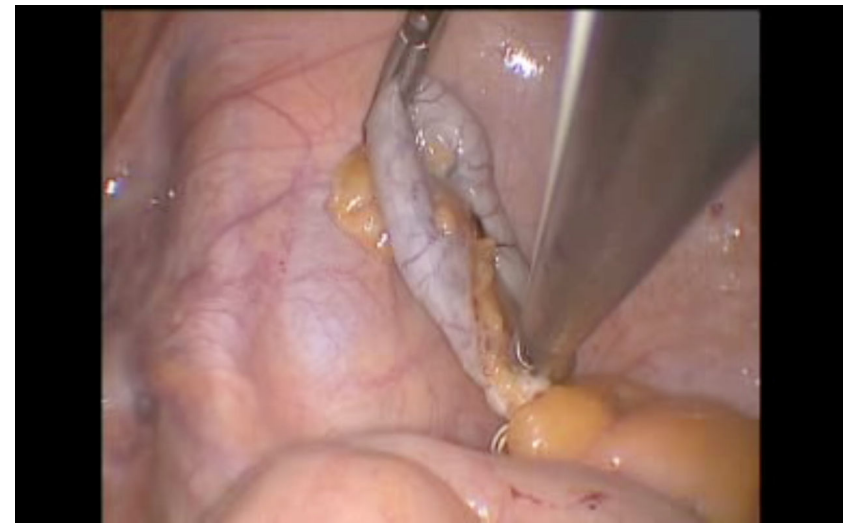

Figure 3. Appendectomy.

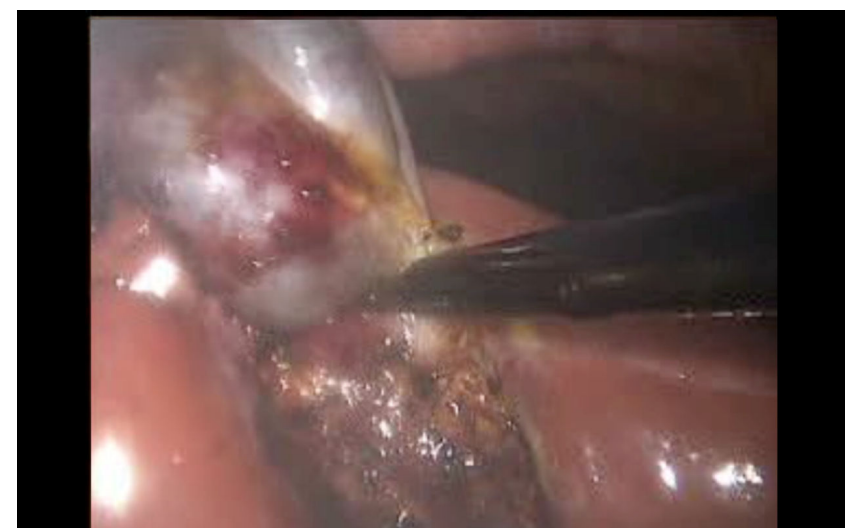

Figure 4. Cholecystectomy.

\section{Results}

The patient characteristics are shown in Table 1. Briefly, six patients had symptomatic complex adnexal masses and three had symptomatic myoma uteri. In two of the patients with 
myoma uteri, an appendectomy (hysterectomy+bso +appendectomy) (Figure 3) was performed concomitantly, and in one of the patients with myoma uteri, a cholecystectomy (hysterectomy+BSO+cholecystectomy) (Figure 4) was performed concomitantly. In four of the patients with symptomatic adnexal masses, an appendectomy (hysterectomy +bso or uso or cystectomy+appendectomy) (Figure 5) was performed concomitantly and in two of the patients with complex adnexial masses, a cholecystectomy (hysterectomy + USO or USO+cholecystectomy) was performed concomitantly. The mean age of the patients was $47.1 \mathrm{y}$ and the mean duration of surgery was $128 \mathrm{~min}$. All patients were treated using straight, non-roticulating laparoscopic instruments. The mean diameter of the tumors was $5.5 \mathrm{~cm}$ (range: $3-9 \mathrm{~cm}$ ) in patients with adnexial masses. All patient pathology reports were benign and procedures for all patients were not converted to laparotomy. All patients were discharged on postoperative D1. None of the patients required a hospital readmission. Post-surgery, all the patients reported that they were satisfied with their incisions and cosmetic results (Figure 6).

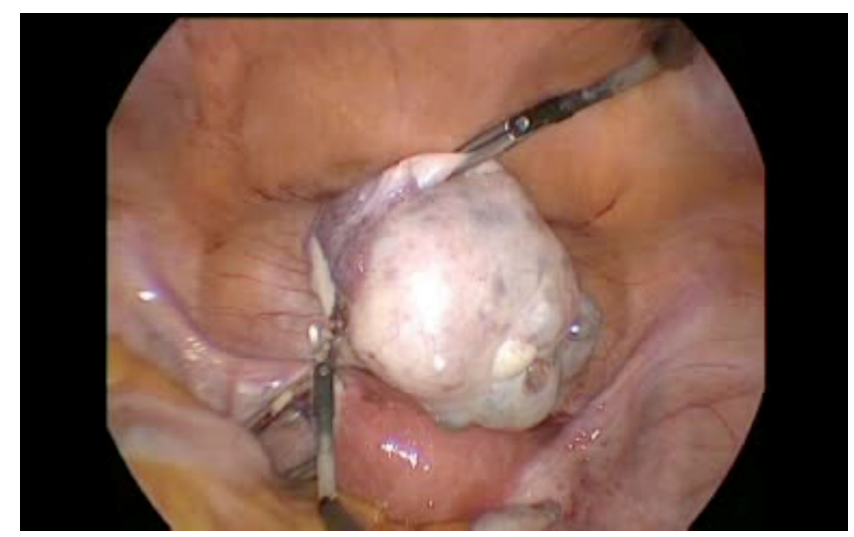

Figure 5. Unilateral Salpingo-oophorectomy.

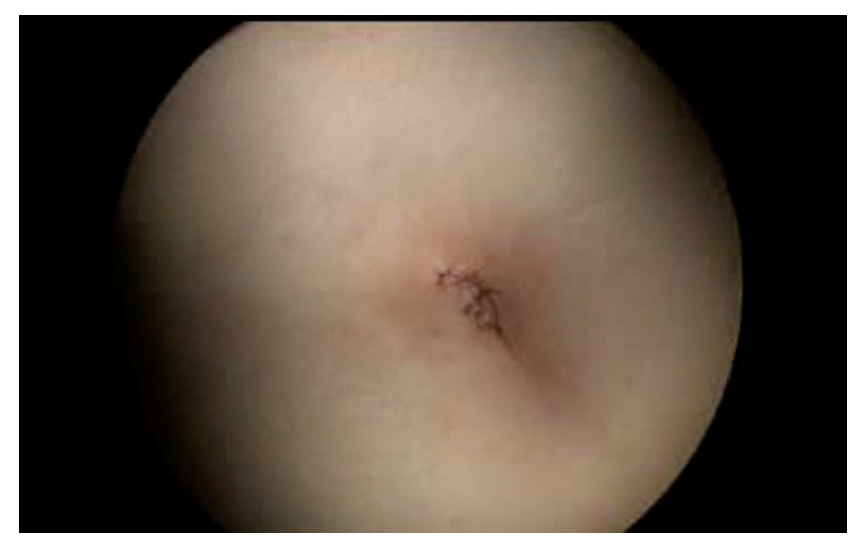

Figure 6. Skin incision after surgery.

\section{Discussion}

SILS is not generally applicable due to be a difficult surgical technique and the need for higher surgical skills. Additionally, instruments of this procedure such as roticulating and curved instruments is more expensive than conventional laparoscopic instruments [9]. However, SILS causes less scars than does the conventional laparoscopy and scarless surgery represents the future of surgery. As a result, there is an increasing interest in SILS by surgeons, patients, and the entire healthcare industry $[10,11]$. In our study, we performed single incision laparoscopy for three cholecystectomies and six appendectomies concomitantly with ovarian cystectomy, unilateral salpingooopherectomy or hysterectomy with unilateral salpingooopherectomy or bilateral salpingo-oopherectomy. General surgical procedure is typically performed with using three to four ports for classical laparoscopic cholecystectomy or appendectomy. The first trocar is placed to the umbilicus and the other two $5 \mathrm{~mm}$ trocars are placed to a right and left subcostal region. Conversely, the site of secondary ports chosen by gynecologists is different: two $5 \mathrm{~mm}$ ports are usually placed lateral to the inferior epigastric vessels bilaterally, and one 5 or $10 \mathrm{~mm}$ port suprapubically. In interventions performed simultaneously by a surgeon and a gynecologist, an increased number of ports are needed, as many as five or six, to ensure the safe and ergonomic completion of each procedure. Additional skin incisions involve the risk of wound complications such as infection, bleeding, herniation, and a bad aesthetic outcome. They also may increase pain. We consider that a multiple procedure performed with a single incision is easier than a classical multiport surgery. Further, we think that SILS reduces the number of trocars used in conventional laparoscopy for multiple procedures, and decreases the risk of wound complications. In the literature, Surica et al. reported concomitant ovarian cystectomies and cholecystectomies using a multi-instrument access port, and Hart et al. discussed a concomitant SILS cholecystectomy and hysterectomy. Jun et al. reported 41 patients who underwent concomitant procedures (cholecystectomy, ovarian cystectomy, appendectomy, ventral hernia repair, varicocelectomy and splenectomy) with using SILS. They concluded that complex concomitant procedures can be performed using the SILS approach [12-14].

Scarless surgery represents the future of surgery so the development of medical industries and surgical techniques are towards less invasive technique than conventional laparoscopy such as minilaparoscopy, natural orifice translumenal endoscopic surgery and single-incision laparoscopic surgery [15-17]. In minilaparoscopy, size of skin incision is reduced (due to using of $3 \mathrm{~mm}$ ancillary trocars instead of $5 \mathrm{~mm}$ trocars) however number of skin incision and morbidities are equal to conventional laparoscopy [18]. Because of these disadvantages of minilaparoscopy, recent years there has been increasing interest for single incision laparoscopic techniques which reduces number of skin incisions and related complications [19,20]. As a result, there is an increasing interest in SILS by surgeons, patients, and the entire healthcare industry. In our study, we used the transumbilical approach with a $2.0-2.5 \mathrm{~cm}$ incision, which resulted in a better cosmetic outcome and an almost normal-looking umbilicus in all nine patients than did the supraumbilical and intraumbilical approaches. 
In conclusion, SILS is feasible for the treatment of adnexal masses concomitantly with other general surgical indications such as appendectomies or cholecystectomies. Further, the use of SILS when performing simultaneous gynecological procedures, appendectomies or cholecystectomies can result in better aesthetic results and cause less postoperative morbidity such as surgical site infection, bleeding, adhesion formation and hernia than conventional laparoscopy. The small patient population available to us and the retrospective design of the study are the limitations of the present study. Additional research with larger patient population is needed.

Table 1. Patient characteristics.

\begin{tabular}{|c|c|c|c|c|c|}
\hline Patients no & Age $(Y)$ & Type of adnexal masses & Concomitant operation & Type of operation & Pathology \\
\hline 1 & 44 & Myoma uteri & Appendectomy & Myomectomy+appendectomy & Myoma uteri, appendicitis \\
\hline 2 & 66 & $\begin{array}{l}4 \mathrm{~cm} \text { complex ovarian } \\
\text { cysts }\end{array}$ & Cholecystectomy & USO+cholecystectomy & $\begin{array}{l}\text { Mucinous } \\
+ \text { cholecystitis }\end{array}$ \\
\hline 3 & 48 & Myoma uteri & Appendectomy & Hysterectomy+BSO appendectomy & Myoma uteri, appendicitis \\
\hline 4 & 30 & $\begin{array}{l}6 \mathrm{~cm} \text { complex ovarian } \\
\text { cysts }\end{array}$ & Appendectomy & USO+appendectomy & $\begin{array}{l}\text { Mucinous } \\
\text { +appendicitis }\end{array}$ \\
\hline 5 & 54 & $\begin{array}{l}\text { Myoma Uteri+ovarian } \\
\text { cysts }\end{array}$ & Cholecystectomy & Hysterectomy+BSO+cholecystectomy & Myoma uteri, cholecystitis \\
\hline 6 & 45 & $9 \mathrm{~cm}$ ovarian cysts & Cholecystectomy & USO+cholecystectomy & Torsione cysts+cholecystitis \\
\hline 7 & 48 & $6 \mathrm{~cm}$ ovarian cysts & Appendectomy & Hysterectomy+BSO+appendectomy & Mature cystic teratome, appendicitis \\
\hline 8 & 63 & $\begin{array}{l}\text { Myoma uteri+ovarian } \\
\text { cysts }\end{array}$ & Cholecystectomy & Hysterectomy+USO+cholecystectomy & Myoma uteri, Cholecystitis \\
\hline 9 & 26 & Ovarian cysts & Appendectomy & Cystectomy+appendectomy & Appendicitis \\
\hline
\end{tabular}

\section{Conflict of Interest}

None

\section{Funding}

None

\section{References}

1. Fader AN, Rojas-Espaillat L, Ibeanu O, Grumbine FC, Escobar PF. Laparoendoscopic single-site surgery (LESS) in gynecology: a multi-institutional evaluation. Am J Obstet Gynecol 2010; 203: 1-6.

2. Fransen S, Stassen L, Bouvy N. Single incision laparoscopic cholecystectomy: A review on the complications. J Minim Access Surg 2012; 8: 1-5.

3. Desai MM, Rao PP, Aron M. Scarless single port transubilical nephrectomy and pyeloplasty: first clinical report. BJU Int 2008; 101: 83-88.

4. Romanelli JR, Earle DB. Single-port laparoscopic surgery: an overview. Surg Endosc 2009; 23: 1419-1427.

5. Wadhwa A, Chowbey PK, Sharma A, Khullar R, Soni V, Baijal M. Combined procedures in laparoscopic surgery. Surg Laparosc Endosc Percutan Tech 2003; 13: 382-386.

6. Bisgaard T, Klarskov B, Trap R, Kehlet H, Rosenberg J. Microlaparoscopic vs. conventional laparoscopic cholecystectomy: a prospective randomized double-blind trial. Surg Endosc 2002; 16: 458-464.
7. Yoo EH, Shim E. Single-port access compared with threeport laparoscopic adnexal surgery in a randomized controlled trial. J Int Med Res 2010; 41: 673-680.

8. Dursun P, Tezcaner T, Zeyneloglu HB, Alyazici I, Haberal A, Ayhan A. Ad-nexal masses treated using a combination of the sils port and noncurved straight laparoscopic instruments: Turkish experience and review of the literature. Minim Invasive Surg 2013; 2013: 836380.

9. Sinha R. Single-incision laparoscopic transabdominal preperitoneal inguinal hernia repair using only conventional instruments: an initial report. J Laparoendosc Adv Surg Tech A 2011; 21: 335-340.

10. Cho YJ, Kim ML, Lee SY, Kim JM, Joo KY. Laparoendoscopic single-site surgery (LESS) versus conventional laparoscopic surgery for adnexal preservation: a randomized controlled study. Int J Womens Health 2012; 4: 85-91.

11. Song T, Kim ML, Jung YW, Yoon BS, Joo BS, Seong SJ. Laparoen-doscopic single-site versus conventional laparoscopic gynecologic surgery: a metaanalysis of randomized controlled trials. Am J Obstet Gynecol 2013; 209: 317.

12. Lee JS, Hong TH, Park BJ, Kim JJ. Transumbilical single port laparoscopic surgery for the treatment of concomitant disease. Minim Invasive Ther Allied Tech 2013; 22: 181-186.

13. Surico D, Gentilli S, Vigone A, Paulli E, Leo L, Surico N. Laparoendoscopic single-site surgery for treatment of concomitant ovarian cystectomy and cholecystectomy. J Minim Invasive Gynecol 2010; 17: 656-659. 
14. Hart S, Ross S, Rosemurgy A. Laparoendoscopic singlesite combined cholecystectomy and hysterectomy. J Minim Invasive Gynecol 2010; 17: 798-801.

15. Navarra G, La Malfa G, Lazzara S, Ullo G, Curro G. SILS and NOTES cholecystectomy: a tailored approach. J Laparoendosc Adv Surg Tech A 2010; 20: 511-514.

16. Lim MC, Kim TJ, Kang S, Bae DS, Park SY, Seo SS. Embryonic natural orifice transumbilical endoscopic surgery (E-NOTES) for adnexal tumors. Surg Endosc 2009; 23: 2445-2449.

17. Desai MM, Rao PP, Aron M, Pascal-Haber G, Desai MR, Mishra S, Kaouk JH, Gill IS. Scarless single port transumbilical nephrectomy and pyeloplasty: first clinical report. BJU Int 2008; 101: 83-88.

18. Ghezzi F, Cromi A, Columbo G. Minimizing ancillary ports size in gynecologic laparoscopy: a randomized trial. J Minim Invasive Gynecol 2005; 12: 480-485.
19. Madureira FA, Manso JE, Madureira Filho D, Iglesias AC. Inflammation in laparoendoscopic single-site surgery versus laparoscopic cholecystectomy. Surg Innov 2013; 21: 263-268.

20. Trastulli S, Cirocchi R, Desiderio J. Systematic review and meta-analysis of randomized clinical trials comparing single-incision versus conventional laparoscopic cholecystectomy. Br J Surg 2013; 100: 191-208.

\section{*Correspondence to}

Polat Dursun

Department of Obstetrics and Gynecology

Baskent University School of Medicine

Turkey 